\title{
Hydrochemical characterization in shallow geothermal system operation
}

\author{
BYOUNG OHAN SHIM ${ }^{1 *}$, HANNA CHOI ${ }^{2}$, JAEYEON KIM ${ }^{3}$,
}

${ }^{1}$ Korea Institute of Geoscience and Mineral Resources

(KIGAM); E-mail: boshim@kigam.re.kr

${ }^{2}$ Korea Institute of Geoscience and Mineral Resources

(KIGAM); E-mail: pythagoras84@kigam.re.kr

${ }^{3}$ Seoul National University; E-mail: jaeyon3@snu.ac.kr

The shallow geothermal system utilizes groundwater temperature for cooling and heating of buildings through groundwater circulation. For a long-term operation of geothermal system, it is important to evaluate the influences of geochemical properties of groundwater which can involve precipitation or dissolution of secondary minerals during circulation. This research monitored well for hybrid GHP (groundwater heat pump) system of 150-meter depth with 30meter interval, adjacent 4 wells, and surface water for before heating operation (January), heating operation (February), and before cooling operation (June) periods in 2019.

Hydrochemical data of geothermal well reflect active vertical mixing of groundwater but horizontal mixing with surface water did not take place during the GHP operation. The major ion ratios of the groundwater on the Piper diagram appear as either the $\mathrm{Ca}-\mathrm{HCO} 3$ type or the $\mathrm{Na}-\mathrm{Ca}-\mathrm{Cl}$ type depending on the influence of heat pump operation and external substances. Groundwater evolution seems to take place from the well located on the northwestern side of geothermal well when referring to the signs from the continuity of water table variation, temperature change, and the $87 \mathrm{Sr} / 86 \mathrm{Sr}$ isotope distribution. In order to predict secondary mineral precipitation or dissolution of geothermal well from the GHP operation, this study estimated the Saturation Index (SI) using the PHREEQC program. The calculated SI values showed that Manganese oxides are much more sensitive to temperature changes than carbonate minerals. In addition, saturation condition can change by the mineral-bearing ion concentration. Thus, the hydrochemical differences based on the depth of shallow geothermal system are related to different mineral precipitation and dissolution.

This research was supported by the Basic Research Project (20-3411) of the Korea Institute of Geoscience and Mineral Resources (KIGAM) granted by the Ministry of Science and ICT. 